\title{
Mesoporous Zn/Co/Fe Layered Double Hydroxide Nanoparticles at Different Temperatures: Hydrothermal Synthesis and Characterisation
}

\author{
PRIYADARSHI ROY CHOWDHURY ${ }^{* a}$, HIMANI MEDHI ${ }^{\mathrm{a}}$, \\ SATYAJEET KUMAR ${ }^{\mathrm{b}}$ and KRISHNA G. BHATTACHARYYA ${ }^{\mathrm{a}}$ \\ ${ }^{\text {a } D e p a r t m e n t ~ o f ~ C h e m i s t r y, ~ G a u h a t i ~ U n i v e r s i t y, ~ G u w a h a t i-781014, ~ A s s a m, ~ I n d i a ~}$ \\ ${ }^{\mathrm{b}}$ Department of Chemistry, Hojai College, Hojai College, Hojai-782435, Assam, India \\ priyadarshiroychowdhury@yahoo.in
}

Received 17 January 2013 / Revised 17 February 2013 / Accepted 14 March 2013

\begin{abstract}
The $\mathrm{Zn} / \mathrm{Co} / \mathrm{Fe}$-layered double hydroxide nanowires are synthesized via a reverse microemulsion method by using cetyltrimethyl ammonium bromide (CTAB)/n-hexane/n-hexanol/water as soft-template. For the purpose of synthesis of $\mathrm{ZnSO}_{4} \cdot 7 \mathrm{H}_{2} \mathrm{O}, \mathrm{CoSO}_{4} \cdot 7 \mathrm{H}_{2} \mathrm{O}, \mathrm{Fe}_{2}\left(\mathrm{SO}_{4}\right)_{3} .7 \mathrm{H}_{2} \mathrm{O}$ and urea were used as raw materials. The synthesized LDHs are characterised by powder $x$-ray diffraction (PXRD), Fourier Transformed-Infrared spectroscopy (FT-IR) and high resolution transmission electron microscope (HR-TEM). The characterised data revealed that the resulting $\mathrm{Zn} / \mathrm{Co} / \mathrm{Fe}-\mathrm{LDHs}$ possessed high crystallinity, microspheric morphology and porous structure to be potentially used as catalyst. Thus, the present work has demonstrated the low-cost and the easiest way of synthesizing the LDHs which could be applied potentially as a multifunctional catalyst in the field of materials science.
\end{abstract}

Keywords: Microemulsion, Nanowires, Template, Multifunctional, Porosity, Crystallinity

\section{Introduction}

Layered double hydroxides (LDHs), also known as anionic clays, are a family of compounds which are deserving much attention in recent years ${ }^{1-3}$. The structure of most of them corresponds to that of hydrotalcite, a natural magnesium-aluminum hydroxycarbonate, discovered in Sweden around 1842. It occurs in nature in foliated and contorned plates of fibrous masses. Its formula is $\mathrm{Mg}_{6} \mathrm{Al}_{2}(\mathrm{OH})_{16} \mathrm{CO}_{3} \cdot 4 \mathrm{H}_{2} \mathrm{O}$. Due to the relationship between its structure and that of brucite, $\mathrm{Mg}(\mathrm{OH})_{2}$, it is usually formulated as $\left[\mathrm{Mg}_{0.75} \mathrm{Al}_{0.25}(\mathrm{OH})_{2}\right]$ $\left(\mathrm{CO}_{3}\right)_{0.125} \cdot 0.5 \mathrm{H}_{2} \mathrm{O}$. Brucite shows the well-known $\mathrm{CdI}_{2}$-type structure, i.e. a hexagonal closepacking of hydroxyl ions, with all octahedral sites every two interlayers are occupied by $\mathrm{Mg}^{2+}$ ions. Partial $\mathrm{Mg}^{2+} / \mathrm{Al}^{3+}$ substitution gives rise to positively charged layers, thus leading to the location of anions in the unoccupied inter-layers. Cavani et al. ${ }^{4}$ synthesized LDHs by the co-precipitation method typically by mixing an alkaline solution alongwith a mixed 
solution containing divalent and trivalent metal cations. Moreover, Xu et al. ${ }^{5,11}$ investigated that the preparation of LDHs by the co-precipitation method is relatively easy, but it forms large aggregates of sheet-like LDH nanocrystallites. In order to disperse LDH aggregates into individual small crystallites, they developed a method involving a fast co-precipitation and washing followed by controlled hydrothermal reaction.

Most of the applications of LDHs correspond to the field of heterogeneous catalysis ${ }^{6}$, where the choice of different metal cations (hydrotalcites have been also prepared containing two or more different $\mathrm{M}^{2+}$ or $\mathrm{M}^{3+}$ cations in the brucite-like layers) make these materials rather suitable for a fine modulation of chemical composition and hence enhance its catalytic properties. On the other hand, as the cations in hydrotalcites are well dispersed, heterogeneous catalysts obtained upon thermal decomposition usually show a high dispersion of the metal sites. The use of microporous and mesoporous molecular sieve materials in catalysis, including LDHs and pillared LDHs, has been recently reviewed ${ }^{5}$. Moreover LDHs have attracted a great deal of interest as anion exchangers, ionic conductors and additives for various polymers and other functional materials ${ }^{8-12}$. The combination of unique properties of LDHs with magnetic materials has offered a new perspective in drug delivery systems. The environmental deterioration accompanied by energy shortage has become the major obstacle to the development of economy and society in the past decades for which photocatalysis using semiconductors has been extensively investigated. Recently Garcia-et al. ${ }^{15}$ reported the visible oxygen generation from water with photocatalysis of $\mathrm{Zn}-\mathrm{M} \mathrm{LDH}(\mathrm{M}=\mathrm{Cr}, \mathrm{Ti}, \mathrm{Ce})$ and the results showed that the LDH can be regarded as "doped semiconductors".

In this work, the $\mathrm{Zn} / \mathrm{Co} / \mathrm{Fe}-\mathrm{LDHs}$ have been synthesized via reverse microemulsion by using cetyltrimethyl ammonium bromide (CTAB) $/ n$-hexane/ $n$-hexanol/water as softtemplate. The LDHs has been characterized in detail using P-XRD, TEM and FT-IR spectroscopy. Thus this work provided a facile approach for the synthesis of $\mathrm{Zn} / \mathrm{Co} / \mathrm{Fe}$ $\mathrm{LDH}$, which can be of great importance in the diversified fields of materials research.

\section{Experimental}

All the analytical grade chemicals including $\mathrm{ZnSO}_{4} .7 \mathrm{H}_{2} \mathrm{O}, \mathrm{CoSO}_{4} \cdot 7 \mathrm{H}_{2} \mathrm{O}, \mathrm{Fe}_{2}\left(\mathrm{SO}_{4}\right)_{3} .7 \mathrm{H}_{2} \mathrm{O}$ and urea were purchased from the Merck Chemical Co. U.S.A. and used without further purification. The deionized and decarbonated water was used in all the preparation processes.

\section{Catalyst synthesis}

The catalysts were synthesized by the co-precipitation of $\mathrm{Zn}, \mathrm{Co}$ and Fe-salts respectively from their homogenous solution. A quaternary microemulsion comprising of cetyltrimethylammonium bromide (CTAB)/water/ $n$-hexane $n$-hexanol was selected for the synthesis of $\mathrm{Zn} / \mathrm{Co} / \mathrm{Fe}-\mathrm{LDH}$. The solution was prepared by dissolving $5 \mathrm{~g} \mathrm{CTAB}$ in $130 \mathrm{~mL}$ of $n$-hexane and $15 \mathrm{~mL}$ of $n$-hexanol. The solution was stirred vigorously in a magnetic stirrer for $2 \mathrm{~h}$. Next, $10 \mathrm{~mL}$ of each of the solution containing the sulfates of the elements in their respective molar ratios $\mathrm{Zn}: \mathrm{Co}: \mathrm{Fe}=1: 2: 1$ and $10 \mathrm{~mL}$ of $0.5 \mathrm{M}$ urea aqueous solution were added to the solution. After substantial stirring, the resulting microemulsion solution was then transferred into a stainless Teflon lined autoclave and heated at $80{ }^{\circ} \mathrm{C}, 100{ }^{\circ} \mathrm{C}, 120{ }^{\circ} \mathrm{C}$ and $180{ }^{\circ} \mathrm{C}$ respectively in each case for $12 \mathrm{~h}$, then cooled to room temperature. The final precipitate was centrifuged, washed and dried. In all preparations urea was used as the basic precipitating agent.

\section{Characterization}

Powder $x$-ray diffraction of $\mathrm{Zn} / \mathrm{Co} / \mathrm{Fe}-\mathrm{LDH}$ samples was taken on a Shimadzu XRD-6000 diffractometer. The infrared absorption spectroscopy was measured on a FT-IR spectrometer 
(Perkin Elmer spectrum one) from 4000 to $400 \mathrm{~cm}^{-1}$. The morphology of the LDHs was investigated using TEM images, which were recorded with Philips TECNAI-20 highresolution transmission electron microscope.

\section{Results and Discussion \\ Characterization of $\mathrm{Zn} / \mathrm{Co} / \mathrm{Fe}-\mathrm{LDHs}$}

XRD spectra analysis

The powder XRD patterns for $\mathrm{Zn} / \mathrm{Co} / \mathrm{Fe}-\mathrm{LDHs}$ with $\mathrm{Zn}: \mathrm{Co}: \mathrm{Fe}$ molar ratio of 1:2:1 respectively is illustrated in Figure 1. A strong reflection $\left(\begin{array}{lll}0 & 0 & 3\end{array}\right)$ was observed for the three samples. Besides this, the XRD patterns showed the reflections of $\left(\begin{array}{lll}0 & 0 & 6\end{array}\right),\left(\begin{array}{lll}0 & 0 & 9\end{array}\right),\left(\begin{array}{lll}1 & 1 & 0\end{array}\right)$ which has been assigned to the typical LDH materials ${ }^{15}$. Other small peaks in Figure 1 (b and c) may be caused by $\mathrm{SO}_{4}{ }^{2-}$. A rhombohdral 3R stacking sequence has been observed in the samples. The lattice parameters ' $\mathrm{a}$ ' and 'c' of the samples synthesized at $100{ }^{\circ} \mathrm{C}$ and $120{ }^{\circ} \mathrm{C}$ has been calculated. Table 1 reveals that the values of $\mathrm{d}_{003} / \mathrm{nm}, \mathrm{d}_{006} / \mathrm{nm}, \mathrm{d}_{110} / \mathrm{nm}$, $\mathrm{a} / \mathrm{nm}$ and $\mathrm{c} / \mathrm{nm}$ were found to be independent of the reaction temperatures.

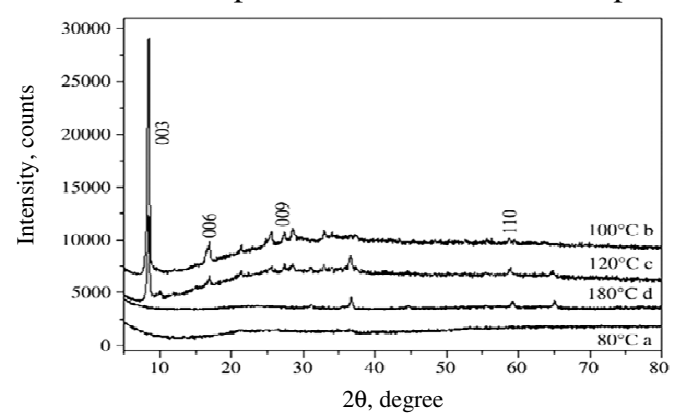

Figure 1. XRD patterns of samples at different temperatures: (a) $80{ }^{\circ} \mathrm{C}$ (b) $100^{\circ} \mathrm{C}$ (c) $120^{\circ} \mathrm{C}$ (d) $180{ }^{\circ} \mathrm{C}$

Table 1. Indexing of P-XRD patterns of the LDHs at different temperatures

\begin{tabular}{cccccc}
\hline Temperature & $\mathrm{d}_{003} / \mathrm{nm}$ & $\mathrm{d}_{006} / \mathrm{nm}$ & $\mathrm{d}_{110} / \mathrm{nm}$ & $\mathrm{a} / \mathrm{nm}$ & $\mathrm{c} / \mathrm{nm}$ \\
\hline $100^{\circ} \mathrm{C}$ & 1.048 & 0.523 & 0.157 & 0.314 & 3.142 \\
$120^{\circ} \mathrm{C}$ & 1.048 & 0.524 & 0.157 & 0.314 & 3.141 \\
\hline
\end{tabular}

According to the Scherrer equation: $D=K \lambda / \beta(\cos \theta)$, the crystallite size of sample ' $c$ ' is $48.5 \mathrm{~nm}$, which is larger than $32.5 \mathrm{~nm}$ of sample ' $\mathrm{b}$ '. Here ' $a$ ' represents the average distance between two metal ions in the layers and ' $c$ ' is three times the distance from the centre of one layer to the next. The value of a $\left(=2 \mathrm{~d}_{110}\right)$ is a function of the average radii of the metal cations whereas the value of $\mathrm{c}\left(=3 \mathrm{~d}_{003}\right)$ is a function of the average charge of the metal cations.

\section{FT-IR spectra analysis}

The FT- IR spectra of LDHs prepared at $100{ }^{\circ} \mathrm{C}$ and $120{ }^{\circ} \mathrm{C}$ (Figure 2) revealed two broad absorptions from 2700 to $3700 \mathrm{~cm}^{-1}$ due to the stretching mode of hydrogen-bonded hydroxyl groups, both from the brucite-like layers and interlayer water molecules. The bending mode band of water molecules, usually observed close to $1600 \mathrm{~cm}^{-1}$, is recorded at $1625 \mathrm{~cm}^{-1}$ in the case of $\mathrm{Zn} / \mathrm{Co} / \mathrm{Fe}-\mathrm{LDH}$. The sharp bands at $1148 \mathrm{~cm}^{-1}$ and $681 \mathrm{~cm}^{-1}$ are attributed to $v_{3}$ and $v_{4}$ bands of the $\mathrm{SO}_{4}{ }^{2-}$ ions respectively, indicating that the interlayer anions of the $\mathrm{Zn} / \mathrm{Co} / \mathrm{Fe}-\mathrm{LDHs}$ are $\mathrm{SO}_{4}{ }^{2-}$ ions. In this case also the observed IR bands were found to be independent of temperature although the $\%$ transmittance was found to differ with respect to temperature. 


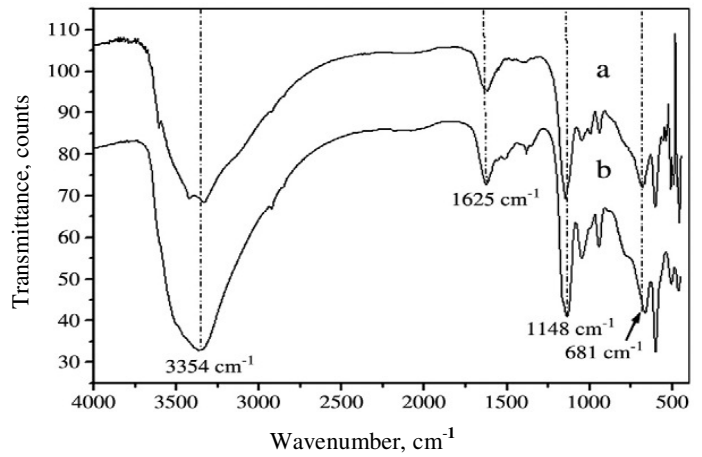

Figure 2. FT-IR spectra of LDHs prepared at (a) $100{ }^{\circ} \mathrm{C}$ and (b) $120^{\circ} \mathrm{C}$

\section{TEM analysis}

The morphology of the samples synthesized at different temperatures for $12 \mathrm{~h}$ has been examined via TEM. The samples formed from 80 to $120{ }^{\circ} \mathrm{C}$ are with a wire-like shape (Figure 3). As shown in Figure 3b, $\mathrm{Zn} / \mathrm{Co} / \mathrm{Fe}-\mathrm{LDH}$ s prepared at $100{ }^{\circ} \mathrm{C}$ maintain a nanowire morphology that is uniform in shape and size, with diameter of about $10 \mathrm{~nm}$ and length up to about 100-600 $\mathrm{nm}$. Figure $3 \mathrm{c}$ shows that nanowires and nanoparticles co-existed in the $\mathrm{Zn} / \mathrm{Co} / \mathrm{Fe}-\mathrm{LDHs}$ obtained at $120^{\circ} \mathrm{C}$ and the nanowires are with smaller aspect ratio. When the temperature was up to $180{ }^{\circ} \mathrm{C}$, the sample was almost in morphology of particles. The small particles that existed in the sample prepared at $120{ }^{\circ} \mathrm{C}$ show the composite oxide structure. They have different structures with the wire-like ones. From the micrographs it is very clear that the morphology and size of $\mathrm{Zn} / \mathrm{Co} / \mathrm{Fe}-\mathrm{LDHs}$ strongly depend on the temperature. When hydrothermal temperature is increased, the reverse micelles in the microemulsion cannot be maintained that would result in fast cluster nucleation oriented in random directions, when the particles were formed ${ }^{14-18}$. The TEM micrographs of $\mathrm{Zn} / \mathrm{Co} / \mathrm{Fe}-$ $\mathrm{LDH}$ samples prepared at $100{ }^{\circ} \mathrm{C}$ for different reaction times is displayed in the Figure 4 . It is evident from the images that the samples obtained at 6 to $24 \mathrm{~h}$ were all nanowires, whose length and diameter increased with the prolongation of time.
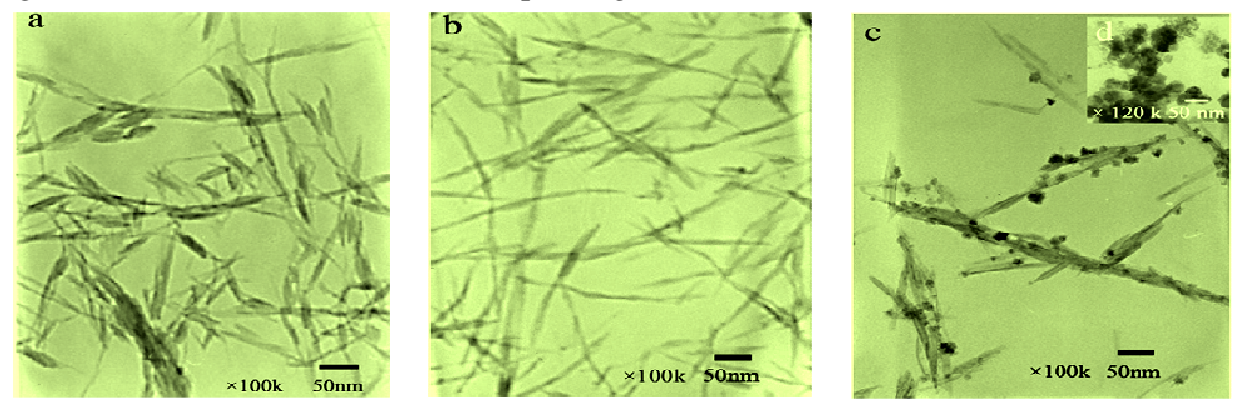

Figure 3. TEM micrographs of samples prepared at different temperatures: (a) $80{ }^{\circ} \mathrm{C}$ (b) $100{ }^{\circ} \mathrm{C}$ (c) $120^{\circ} \mathrm{C}$ and (d) $180{ }^{\circ} \mathrm{C}$

From the Figure $4 \mathrm{a}$, it is clear that the $\mathrm{Zn} / \mathrm{Co} / \mathrm{Fe}-\mathrm{LDHs}$ were nanowires with 5-10 nm in diameter and $50-200 \mathrm{~nm}$ in length. Figure $4 \mathrm{~b}$ shows that $\mathrm{Zn} / \mathrm{Co} / \mathrm{Fe}-\mathrm{LDHs}$ prepared at $100{ }^{\circ} \mathrm{C}$ maintain a nanowire morphology which is uniform in shape and size, with diameter of about $10 \mathrm{~nm}$ and length up to about 100-600 $\mathrm{nm}$. The TEM micrographs in the case of $24 \mathrm{~h}$ showed that the sizes of nanowires (Figure 4c) are almost the same as those prepared at $12 \mathrm{~h}$. 

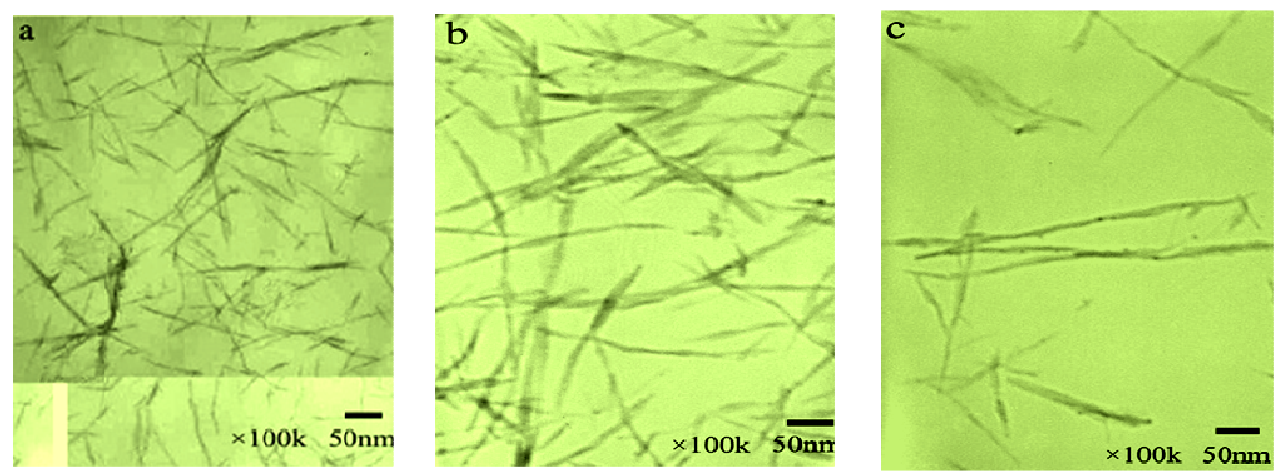

Figure 4. TEM micrographs of LDH nanowires prepared at different times: (a) 6 h, (b) $12 \mathrm{~h}$, and (c) $24 \mathrm{~h}$

\section{Conclusion}

Thus $\mathrm{Zn} / \mathrm{Co} / \mathrm{Fe}-\mathrm{LDH}$ nanowires were successfully prepared via the microemulsion by hydrothermal process at different temperatures. It is observed that the temperature played an important role in the structure and morphology for the LDH samples. Amorphous mixed hydroxides with nanowire morphology sample is formed at $80{ }^{\circ} \mathrm{C}$, while nanoparticles besides the $\mathrm{Zn} / \mathrm{Co} / \mathrm{Fe}-\mathrm{LDH}$ nanowires are formed at $120{ }^{\circ} \mathrm{C}$. The optimum conditions of synthesizing uniform $\mathrm{Zn} / \mathrm{Co} / \mathrm{Fe}-\mathrm{LDH}$ nanowires are as follows: $100{ }^{\circ} \mathrm{C}$, more than $12 \mathrm{~h}$ and urea concentration: $0.5 \mathrm{M}$. This route is found to be useful to synthesize other LDH nanowires or rods.

Thus, the layered double hydroxides have deserved its place as topic of research in catalysis in recent years. Its structure, similar to that of layered silicates, but with a change in the sign of the electric charges of the layers and the interlayer ions makes them true companions in systematizing the study of these solids. On the other hand, as the layered cations and the interlayer anions can be almost chosen from anyone in the Periodic Table, the opportunities for synthesis chemistry are enormous. In addition, the promising role that these materials, as obtained or after adequate thermal treatments, can play as catalysts, sensors, electrodes etc., which makes them worthwhile to be studied in a systematic way to modulate and to improve their properties. We hope that the synthesized LDHs will have a myriad of applications in the electronic, magnetic and catalytic areas in future.

\section{Acknowledgment}

The authors are thankful to the Department. of Chemistry, IIT Guwahati for P-XRD and TEM analysis. The authors also sincerely acknowledge the Department of Chemistry, Gauhati University for all kinds of support for this work.

\section{References}

1. Choi H, Sofranko A C and Dionysiou D D, Adv Funct Mater., 2006, 16(8), 1067-1074.

2. Gursky J A, Blough S D, Luna C, Gomez C, Luevano A N and Gardner E A, J Am Chem Soc., 2006, 128(26), 8376-8377.

3. Leroux F and Besse J P, Chem Mater., 2001, 13(10), 3507-3515.

4. Cavani F, Trifirò F and Vaccari A, Catal Today, 1991, 11(2), 173-301.

5. $\quad \mathrm{Xu}, \mathrm{Z} \mathrm{P}$ and Lu G Q, Chem Mater., 2005, 17(5), 1055-1062.

6. Darder M, Lopez-Blanco M, Aranda P, Leroux F and Ruiz-Hitzky E, Chem Mater., 2005, 17(8), 1969-1977. 
7. Gardner E, Huntoon K M and Pinnavaia T J, Adv Mater., 2001, 13(16), 1263-1266.

8. Verionica M, Graciela B, Norma A and Miguel L, Chem Eng J., 2008, 138, 602-607.

9. Zhao Y, Xiao F F and Jiao Q Z, Bull Mater Sci., 2008, 31(6), 831-844.

10. Ay A N, Zümreoglu-Karan B, Temel A and Rives V, Inorg Chem., 2009, 48(18), 8871-8877.

11. Xu Z H, Xu L, Lai Q Y and Ji X Y, Mater Chem Phys., 2007, 105(1), 80-85.

12. Jayashree R S and Vishnu Kamath P, J Power Sources, 2002, 107(1), 120-124.

13. Zhao Y, Jiao Q Z, Ding X J, Zhang L Q and Liu Y Y, Chem Res Chinese U, 2007, 23(5), 622-624.

14. Jiao Q Z, Tian Z L and Zhao Y, J Nanopart Res., 2007, 9(3), 519-522.

15. Garcia H, Silva C G, Bouizi Y and Fornes V, J Am Chem Soc., 2009, 131(38), 1383313839.

16. Fogg A M, Green V M, Harvey H G and O'Hare D, Adv Mater., 1999, 11(17), 14661469.

17. Yang L, Shahrivari Z, Paul K T Liu, Sahimi M and Tsotsis T T, Ind Eng Chem Res., 2005, 44(17), 6804-6815.

18. Hu G and O'Hare D, J Am Chem Soc., 2005, 127(50), 17808-17813. 